\title{
Mundialização, trabalho social e política do sujeito
}

\section{Mundialization, social work and subject's policy}

(Jean BIARNES ${ }^{1}$ )

Tradução:

Nilce da SILVA,

Patrícia FRIDMAN

e Cláudia CASCAPERA

\begin{abstract}
RESUMO
O artigo apresenta algumas possibilidades de uma política do sujeito, abrangendo as questões da ética e da democracia, partir da análise do trabalho realizado em dois grupos do Programa EQUAL. Esses grupos acompanham a inserção social de jovens na França. Para o autor, eles deveriam avaliar-se levando em consideração, ao mesmo tempo, a dimensão quantitativa e a dimensão qualitativa em relação à pessoa enquanto sujeito. Desse modo, surge como conseqüência urgente que os atores sociais se preocupem em construir seus próprios instrumentos de avaliação do seu trabalho, instrumentos de avaliação qualitativa e não quantitativa, respeitando-se uma verdadeira dinâmica do sujeito, tanto do lado do usuário como do ator social na qual cada um tem a necessidade de se "desvendar" (biografização recíproca), de explicitar seus critérios sob o olhar das situações vividas em comum (re-territorialização da pessoa) e de tentar permanecer coerente (desparcialização da pessoa dentro dos diferentes percursos). Todo esse trabalho deve levar em conta que "ser sujeito" não pode jamais ser isolado do objeto. O "ser sujeito" é um "ser em situação”. "Ser sujeito" é ser um "sujeito que fala e que age", ou seja, um "sujeito que deseja”, num cenário social em que o domínio mundial é demarcado pelas fronteiras imprecisas dentro de suas concretizações e de uma extrema eficácia dentro dos seus funcionamentos. Nesse contexto, educar - formar,

1 Título Original : Mondialisation, travail social et politique du sujet
\end{abstract}


acompanhar a dimensão do desejo criativo do sujeito - é a primeira missão que deveria ser dada a todo trabalhador social, por ele mesmo e pelo seu trabalho com o Outro. Este conhecimento do sujeito e da sua própria palavra implica que o ator social "faça com” o sujeito e não "para” o sujeito.

Palavras-chave: ator social, inserção social, mundialização, sujeito, trabalho social.

\begin{abstract}
The article presents some possibilities for a subject's policy envolving question of ethics and democracy. It is based on the analysis of a work realized by two groups of the EQUAL Program. These groups accompany the social insertion of young people in France. According to the author, they should evaluate their social work taking into account, at the same time, the quantitative dimension and the qualitative dimension in relation to the person as subject. This way, it comes to sight an urgent consequence that social actors get worry about constructing their own evaluator's instruments of their work, in order to a qualitative and no quantitative evaluate, respecting a real subject's dynamic, from the user side as well from the social actor side in which each one has the necessity of unveiling (reciprocal "biographization"), explicating their criterions according to their point of view about common lived situations (re"territorialization" of the person) and trying to permanence coherent ("desparcialization" of the person inside different trajectories). All these work ought to take into account that "being subject" can not ever be isolated from the object. The "being subject" is a "being in situation". "Being subject" is to be a "subject who talks and acts", it means, a "subject who desires", in a social scenario in which world-wide dominance is delimited by imprecisely borders inside their concretizations and an extreme efficacy inside their functioning. In this context, to educate - to form, to accompany the dimension of subject's creative desire - is the first mission that should be given to all social worker, by himself and by his work with the Other. This knowledge of the subject and his own word implicates that social actor "works with" instead of "works for" the subject.
\end{abstract}

Index terms: social actor, social insertion, mundialization, subject, social work.

\title{
O que significa "ser sujeito" nos dias de hoje?
}


Se eu tento definir o que "eu sou" em determinado momento, eu devo ser consciente de que, no instante seguinte, eu não sou mais totalmente aquele que eu defini. Isto porque, mesmo que, de modo infinitesimal, o fato, de eu ter me definido, mudou a minha percepção de quem eu sou. O "eu sou” é constituído de um núcleo de permanência e de um estado de transformação perpétua. Definir o “ser sujeito”, é, então, incluir-se nesta “permanência / impermanência”. O “ser” está sempre a criar. Pensar em reduzir esta criação do "ser sujeito” à aprendizagem dos atos impostos e à reprodução é negar a criação ou matá-la. Quando uma sociedade tem este objetivo, ela o atinge seguramente quando se apresenta bem cedo na vida da criança impondo-lhe a reprodução de atos pré-estabelecidos no lugar das capacidades criativas, porém é esta margem de criação que permite ao ser humano não ser totalmente predeterminado socialmente e que representa para nós o "ser sujeito".

O conceito de "ser sujeito" é agora marcado por um selo de "ação perpétua de sua própria criação" e de "uma ação perpétua” no mundo”. É ato assinalado do lugar que lhe foi atribuído do ponto de vista social e cultural. A atividade de criação do "Eu-Sujeito" ligará estreitamente dois níveis de ação e de objetivo: o primeiro nível será a ação, de ordem interna do sujeito sobre ele mesmo, trabalhando para criar ligações de pertencimento ao universal, ao cultural, às diferentes subculturas e ao seu ser singular; o segundo nível será o da ação conduzida pelo sujeito sobre seus arredores e a maneira com a qual ele cria e inscreve seu espaço e sua história individual dentro da história e do espaço coletivos. "Ser sujeito” é, então, o processo da integração inacabada do "eu” à comunidade humana, e também a “transformação que mantém a permanência” do “eu” pela integração dos modelos simbólicos que esta comunidade possui. Escrever sua história, é ter a possibilidade de trabalhar este processo e de criar, de modo cada vez mais autônomo, os laços entre todos estes elementos internos e externos. 
Este processo só pode funcionar se esta ação conduzida conjuntamente sobre si mesmo e sobre seus arredores seja provida de sentidos. É mais fácil, por exemplo, trabalhar com os jovens debutantes do que com os jovens que já sofreram fracassos escolares e exclusão social. Mesmo que exista violência para os primeiros, ela tem um sentido de reivindicação ou de ação contra as dificuldades de integração social, agora, com relação aos segundos, a violência exprime uma luta contra o "non sense". 2

“Ser sujeito” é um processo ativado desde o nascimento. O primeiro "problema” de uma criança é aprender a se excluir do corpo da mãe para se tornar o criador de si mesmo, de sua própria história. O sujeito está sempre dentro desta problemática. Em cada passo da sua vida, este sujeito deverá se excluir do "passado-presente" que ele conhece e que assegura a sua identidade, para entrar na estrangereidade do Outro, o "presente-futuro" que transformará a sua identidade e "não o assegurará”. Todo trabalho educativo e social projeta o sujeito no coração deste movimento com duplo sentido de “inserção/ desinserção". Inserir-se em um espaço novo (a creche, a escola, o mundo do trabalho) implica em perder qualquer coisa do mundo anterior. “Ser sujeito” é poder, no presente, assumir a perda de uma parte do passado face ao ganho esperado do futuro. As políticas sociais, ao oporem “inserção” e "exclusão” fazem um contrasenso. A inserção é apenas uma face deste mecanismo vital de duas faces, "inserção/ desinserção", intrinsicamente ligadas como “Janus” e que simboliza o que é “ser sujeito”.

\footnotetext{
${ }^{2}$ Em 1995, na ocasião de uma pesquisa com crianças de dez anos da periferia sul de Paris, nós havíamos colocado em evidência o profundo estado de depressão das mesmas e escrevemos (BIARNÈS, 1999, p. 177): "se as crianças de dez anos já apresentam quadros de depressão e se a escola não vê e nem entende essa 'diferença', então não é necessário se surpreender com a violência que se manifesta na escola. E ainda, esta pode ser a pior das violências, aquela que não é reivindicativa, e nem é um pedido de socorro, aquela que tem apenas um objetivo, lutar contra o nada. Em novembro de 2005, estas crianças se tornaram jovens de 20 anos! Como interpretar de outra forma o fato de queimarem o carro de pessoas que estavam diariamente ao seu lado, se não pela falta de um sentimento de "ser"? Como compreender que eles também queimaram escolas enquanto em 1995, os jovens encarcerados da antiga FEBEM (Fundação Estadual para o Bem Estar do Menor) em São Paulo, queimaram todos os prédios desta instituição/prisão, exceto... a escola.
} 
Enfim, “ser sujeito” não pode jamais ser isolado do objeto. O "ser sujeito” é um "ser em situação". Esta dinâmica situacional funda a questão do desejo que não sobrevive ao totalitário, pois assim, seria um a-sujeito ou totalmente ligado ao objeto ou desligado do objeto. Salvo os casos patológicos, existe sempre uma falha, uma falta entre sujeito e objeto em uma situação dada, o que faz com que o sujeito seja sempre incompleto e desejante no mundo. “Ser sujeito” é ser um "sujeito que fala e que age”, ou seja, um "sujeito que deseja”.

\section{A mundialização pós-moderna: sociedades em "ilhas" e regras de seleção e de controle.}

A mundialização das relações sociais não datam de hoje (MONGIN, 2005). Se as descobertas dos dois últimos séculos foram transformadas a partir da revolução do tempo vivido pela revolução do transporte e da informação (HABERMAS, 1987), antes mesmo do começo da nossa história moderna, as rotas do sal ou da seda, os grandes movimentos de migração, as cruzadas colocaram em relação os povos do mundo.

Sobre estas relações de mundialização pré-existentes, a época das "grandes descobertas" introduziu uma outra dimensão, a da "hierarquia" entre os mundos. A Europa se coloca em um papel de liderança e olha as outras culturas como se ainda não tivessem seu próprio nível de "civilização". Durante aproximadamente cinco séculos ela pode se fixar em missões de "civilização" e de "emancipação" destas "subculturas", o que lhe permitiu mascarar seus objetivos de exploração dos homens e dos recursos.

Se, dentro desta longa história de conquista e de colonização, os países dominantes puderam situar os "bárbaros” do outro lado do mar, hoje, os “bárbaros”, às vezes, chamados de "selvagens” ou “ralé”, estão do outro lado da rua. A mundialização atual, pela transformação do tempo e do espaço, modificou a territorialização do domínio. As fronteiras nacionais 
não são mais as muralhas da dominação de uns sobre o resto do mundo. Existe a “desnacionalização” e então a “desterritorialização” do poder pela parcelização da nação em “ilhas” no interior das fronteiras nacionais. É aquilo que Miguel Benasayag designa pelo termo “do indivíduo”. “O indivíduo é um número de pessoas ligadas por laços de dinheiro, do proveitoso e do poder” (BENASAYAG, 2004, p. 27). Estas “ilhas” intranacionais formam uma rede internacional de poder graças às novas tecnologias de informação de comunicação. As pessoas componentes destas “ilhas” estão em relação constante com seus alter egos opostos, mas não conversarão com seus vizinhos de corredor.

O pano que constitui hoje o domínio mundial é demarcado pelas fronteiras imprecisas dentro de suas concretizações e de uma extrema eficácia dentro dos seus funcionamentos. As sociedades pós-modernas são então constituídas destes sistemas de "ilhas" fechadas sobre elas mesmas que se auto-alimentam, se auto-reproduzem e se auto-avaliam. O resto é deixado à "barbárie”. Este mundo dual mata a democracia.

Em efeito, quanto mais as fronteiras entre os “territórios” são fluídas, mais elas necessitam, para se assegurar, estar na recusa do Outro diferente e então poder identificá-lo e dominá-lo.

Deve-se ter vivido concretamente os “guetos dos ricos” nos Estados Unidos da América (EUA) para compreender este mecanismo de “comunitarismo/ integrismo” em que “proveito/ poder” é o valor supremo. Estas ilhas são então as máquinas de excluir o outro, mas se as fronteiras nacionais existem para excluir o "bárbaro” que vem do outro lado do mar, elas têm uma eficácia reduzida para excluir aquele que está do outro lado da rua. Deve-se então se dotar de "regras" de escolha e de controle que permitirão identificar facilmente “o que se parece”, e, a fortiori, “o outro”. Para saber e poder colocar cada um do lado correto destas fronteiras fluidas, é necessário que todo o sistema seja “límpido”, “legível” a todo o momento. 
Aparecem agora três tipos de regras, aquelas do "engenheiro", do "médico" e do "contador".

Para o engenheiro, o real deve ser inteiramente controlável já que este é possível de ser controlado do ponto de vista material, já o humano escapa da possibilidade de um controle total. Para acreditar que isto pode ocorrer, o engenheiro, exclui a complexidade por uma segmentação do real que ele poderá controlar ao preço de um racionalismo totalizante que confina ao cientificismo. O "complicado" substitui a complexidade (MORIN, 1992) e o engenheiro sabe agora construir a coisa toda por meio da reunião das partes que ele soube isolar. Este fantasma do "real construído" torna-se para ele, "o real" que ele impôs como tal para o restante da sociedade.

Seus títulos e seus diplomas, certificados pelo nome das grandes escolas de onde este engenheiro saiu, o protegem de questões "ingênuas", sobretudo se elas vem deste outro lado da rua, deste domínio deixado aos "bárbaros"”.

Para que a transparência do sistema seja real, todas as "dobras" e "redobras" da complexidade humana devem desaparecer. O pensamento do engenheiro exlui esta coisa inconveniente que chamam de imaginário, quer dizer “o não dominado” ou, ainda, simplesmente, “o humano”. Quantos são os decisores dentro dos dispositivos da ação social definem como "verborragia" e "perda de tempo" os discursos dos atores sociais que lhes falam da pessoa com a qual eles trabalham cada um dos seus dias? A "coisa humana” é segmentada em partes analisáveis e, então, "deslocalizadas” porque colocá-las reunidas em uma mesma situação reintroduzirá a complexidade.

\footnotetext{
3 Desta forma, o engenheiro pôde construir matadouros ultramodernos em La Vilette, mas teve que demolir simplesmente porque esqueceu questionar o agricultor sobre a inclinação máxima possível para acesso dos animais.
} 
As regras dos engenheiros, estruturadas a partir dos anos sessenta, foram completadas a partir dos anos oitenta pelas regras do médico. Estas regras de higiene do sistema passam pela via da medicalização dos seus possíveis disfuncionamentos, em vista de eliminar a complexidade existente dentro de toda a problemática relacional. Se uma criança apresenta os sintomas da não-adaptação ou da resistência às situações sociais e institucionais, isto só pode ser conseqüência de genes mal formados ${ }^{4}$. Os progressos da genética servem agora de fundamento científico a este tipo de demonstração ${ }^{5}$. Assim, a dislexia não é um problema de domínio da língua pela qual a criança afetada diz alguma coisa para o mundo ao seu redor; ela pode ser uma doença genética e, como prova à escola, não cabe mais aos pedagogos ou psicólogos escolares descobrirem-na, mas sim o médico, dentro de um consultório onde é realizado o exame. E o que dizer do empreendimento de triagem de crianças de três anos ditas "hiperativas" para prevenir a delinqüência quando forem adolescentes? ${ }^{6}$

Enfim, hoje, ao lado das regras do "real controlado" e do "higienismo sistemático", funciona a regra do "contador", a regra do "tudo se pode avaliar" e da rentabilidade máxima. As empresas se tornaram os pilares desta regra não sendo mais uma comunidade de pessoas trabalhando, cada uma no seu nível, na produção de bens. Ela se tornou uma máquina de produzir dinheiro em curto prazo para alimentar as "ilhas” de poder. Os “acionistas”, cada vez mais, a partir de seus fundos de pensão norteamericanas, têm apenas uma obsessão: seus lucros. Reinvestir na pesquisa,

\footnotetext{
${ }^{4}$ Margaret Mead (1935) fazia a mesma constatação com os Arapesh, comunidade da Nova Guiné, organizada sobre princípios de "não violência". Se uma seqüência agressiva se declara entre dois indivíduos, isso poderia ser malefícios enviados pelos índios das planíces. Rituais purificadores cassavam estes malefícios fora da comunidade que podia, desta forma, reencontrar sua pureza original. A ciência genética possui hoje nas nossas comunidades dominantes, a mesma função mágico-religiosa.

${ }^{5}$ Não negamos as causas biológicas nas etiologias deste tipo de perturbação, dizemos somente, como o professor A. Jacquart, que há alguma relação entre o biológico e o relacional para que uma perturbação deste tipo se manifeste

${ }^{6}$ Relatório do Instituto Nacional de Pesquisa médica na França, janeiro de 2006. Esta triagem operada sobre bases biogenéticas lembra perigosamente as piores práticas de uma ideologia que não deveria reaparecer jamais.
} 
na modernização não tem sentido nesta perspectiva. Que dizer então dos investimentos que visam melhorar as condições de trabalho? Estes são apenas “objetos descartáveis”, instrumentos para produzir dinheiro para os acionistas.

O fim do fim do pensamento empreendedor para aumentar a rentabilidade é o licenciamento: a "teoria do açougueiro" substituiu a "teoria do padeiro” (HAMEL; PRAHALAD, 2004). É mais simples, mais controlável, mais “contável”, de amputar a empresa de uma parte dela mesma antes de fazer fermentar o levedo que há dentro de cada sujeito trabalhador no desenvolvimento desta. De que lado da rua está a "barbárie”?

Esta regra de que "tudo pode ser avaliado" e de que pode ser “mais rentável” instaura, portanto, os sistemas que têm os contadores no comando. O “contador” não conhece o sujeito. Acontece que estas regras de rentabilidade, colocada como a Lei Orgânica das Finanças (LOLF), que rege depois de 2006 o orçamento do Estado e as despesas públicas, governa, igualmente, de agora em diante, o mundo da ação social. Face às exigências de rentabilidade a qualquer preço, cada estrutura vai, a curto termo, se encontrar diante da seguinte alternativa: seja colocar as chaves nas portas, seja selecionar o público que lhe permitirá esperar, o mais perto possível, dos objetivos a serem realizados. Cada estrutura social e de inserção se posicionará, então, como uma máquina de excluir os mais frágeis, enquanto ela deveria estar a serviço deles.

Estes sistemas no interior de um Estado fazem desaparecer progressivamente sua função de governar e de organizar a vida social, deixando para ele apenas o papel de garantir as fronteiras das ilhas de domínio contra o resto da sociedade. Para assegurar a legalização e colocar em funcionamento os três tipos de regras anteriormente citadas, o Estado se reduz a não ser mais que o protetor das ilhas de poder. É o “todo repressivo” que predispõe à morte do sujeito (BECK, 2003) dentro de um Estado que se tornou cada vez mais totalitário. 


\section{A injunção paradoxal “de ser sujeito” ao preço “da morte do sujeito”}

Após o nascimento até a sua morte, o sujeito é fortemente incitado a fazer da sua vida "uma obra” (KAUFMAN, 2001; BOURRIAUD, 2003). Dentro da ideologia da sociedade pós-moderna e neoliberal, este individualismo, pregado a cada um por todos, é associado à exigência sacrosanta do "projeto". Ser em si ou para si se define no espírito da construção de um horizonte pessoal integrado a um parecido com o horizonte global definido pelo Estado. Quando se entra em uma missão local, não é necessário esperar muito tempo para ouvir um conselheiro perguntar a um jovem: “Qual é seu projeto?” Para o jovem, que é um sujeito que vive uma situação global, e não simplesmente um usuário da missão local, esta questão e os requisitos que ela contém constituem uma receosa situação de dupla ligação.

A injunção paradoxal que consiste em ordenar a uma pessoa de fazer ao mesmo tempo uma coisa e o seu contrário (a ligação dupla da escola de Palo-Alto) é psiquicamente inviável. Perguntar a um jovem sobre o "seu projeto", quer dizer lhe pedir para ser “sujeito desejante” em um mundo que lhe promete ser licenciado sem motivo algum, apenas engendra “a barbárie”, dito de outro modo, o descontrole do desejo que não tem outra regra se não ele mesmo. Mas esta é a única maneira de evitar a loucura? A loucura ou a barbárie são as alternativas que restarão àqueles que não estão dentro dos sistemas de “domínio internacional”, secreção da mundialização pós-moderna.

Entretanto, este “domínio mundial” tem a necessidade de um resto do mundo que produz e consome, e que escapa então da loucura e da barbárie. Não é esta a verdadeira demanda feita ao trabalho social? Manter uma ligação social, com sentido, onde tudo é ruptura, exclusão, enfermidade 
e falta de senso? Mas, o trabalho social pode responder à esta demanda ainda que será avaliado pelos critérios da rentabilidade, da produtividade, a partir da colocação da LOLF? Submisso, por sua vez, às regras do engenheiro, do médico e do contator, poderá ele manter “o sujeito” dentro dos sistemas que o aninha?

\section{Trabalho social e política do sujeito: uma aposta a ser levada em consideração}

Colocar em funcionamento uma "política do sujeito" é colocar contra o muro estas três regras, que não podem pretender entender a realidade humana. É trabalhar com a complexidade, com as dobras e redobras humanas, suas ambigüidades, suas contradições, e também com seus desejos.

\section{Reintroduzir a complexidade ao liberar a palavra e o imaginário}

Para nós, vejamos em primeiro lugar o que significa liberar a palavra do sujeito. Liberar da prisão da racionalidade científica, liberar dos espaços onde a palavra pode ser dita e entendida. Quando um jovem responde ao conselheiro da missão local que seu projeto é de ser médico ao mesmo tempo em que não domina o conhecimento de base, a primeira reação do conselheiro é lhe mostrar que isso é impossível (regra do engenheiro). Este pragmatismo apoiado sobre uma pretensa lógica dos fatos e o pensamento, contribui para matar mais ainda o sujeito dentro do sujeito. Um projeto está sempre num começo de um projeto imaginário que não é regido pela lógica matemática, mas pela lógica existencial e emocional do sujeito. Esta lógica deve ter o direito de ser dita por todos e não apenas por alguns. Se o conselheiro acolhe a palavra, pesquisa com o jovem o desejo que ele manifesta, pode então confrontar o desejo a uma realidade mais prosaica e 
mostrar a este jovem que este desejo pode se atualizar dentro dos serviços acessíveis, sem jamais fechar a porta da expressão do desejo primeiro.

\section{Desejo, co-construção e espaços de criação}

Educar, formar, acompanhar a dimensão do desejo criativo do sujeito, é a primeira missão que deveria ser dada a todo trabalhador social, por ele mesmo e pelo seu trabalho com o Outro. Colocando em prática esta recomendação com os jovens que recebia dentro de uma missão local em um bairro periférico do norte de Paris, uma estagiária de mestrado ${ }^{7}$ ficou surpresa com as transformações advindas das intervenções do percurso de certos jovens. Um jovem, que ia encontrá-la freqüentemente, se "permite” dizer que, a partir do momento em que ela libera sua palavra da prisão instituída: "Tudo aquilo que a senhora me propôs não me interessa, para mim é a música que interessa”. Trabalhando a partir desta fala, nossa estagiária co-construiu com os jovens um módulo de preparação aos trabalhos em questão. Estes jovens são hoje os técnicos dos festivais ou cantores. Liberar a palavra criativa é trabalhar com o próprio desejo do sujeito e não com aquilo que ele teve que mostrar quando submisso à injunção de “dizer seu projeto”, ele não tem outra solução para escapar de uma má imagem suplementar de si mesmo, que não seja a de definir alguma coisa ao acaso (BIARNÈS, 1993; BIARNÈS; AZOULAY, 1995).

Este conhecimento do sujeito e da sua própria palavra implica que o ator social "faça com” o sujeito e não “para” o sujeito. "Fazer com” é colocar em prática a segunda liberação da palavra, aquela que consiste em fazê-la vir de todo lugar. O altermundialismo, as coordenações de grevistas ou de estudantes, as manifestações das enfermeiras representam antes de tudo o retomar de todas as cenas da vida social do poder da palavra liberada, de que o mundo tem necessidade hoje como “contra poder” à palavra

\footnotetext{
${ }^{7}$ Mestre em engenharia do programa de inserção da Universidade Paris 13.
} 
dominante. Mas, os menores espaços são também os contra-poderes. Nós os temos visto quando preconizamos a um prefeito de dirigir diretamente a palavra aos beneficiários do RMI, mas isto é verdadeiro para cada usuário de um serviço médico-social. Quantos dos cidadãos não ousam nem mesmo interrogar o discurso de um médico, já que este é peremptório e totalitário, queira ou não, o médico jogar com este fato. Há 50 anos, mostra-se aos pais que eles não sabem mais educar, que eles devem chamar os profissionais que eles mesmos formaram e possuem a "esperteza” e a "competência”. O resultado é que hoje os pais são acusados de renúncia pelo Estado ou seus representantes. $\mathrm{O}$ ator social não escapa deste discurso dominante que lhe mascateia e o impede de deixar lugar para a emergência de um discurso de usuário.

\section{Estar "centrado sobre a pessoa" e não "colocá-la no centro de".}

Para se “descentrar” destes hábitos, para ser capaz de promover dentro do seu trabalho estes espaços de palavra, nós preconizamos ao ator social um exercício para se fazer todos os dias: interrogar-se para eliminar certos conceitos “pré-fabricados” que implicam em posturas profissionais próprias para excluir a palavra do sujeito e conseqüentemente o próprio sujeito. "Colocar a pessoas (aluno ou usuário) no centro do dispositivo" educativo ou social, engajar o ator social a pensar e a fazer "para” o sujeito. Estes são os objetos que têm lugar em qualquer parte, não as pessoas. Dentro de um dispositivo totalmente construído em torno da pessoa, qual é o espaço de liberdade dela, senão o da fuga? Um dispositivo concebido “em torno” da pessoa está sobre uma lógica de negação da pessoa como sujeito. Ao contrário, “estar centrado sobre a pessoa” engaja o trabalho social dentro de outra dimensão, aquela do reconhecimento do outro como sujeito desejante, falante e que age. 


\section{A pessoa não está EM dificuldade, ela encontra dificuldades}

Do mesmo jeito, preconizamos eliminar o vocábulo de "pessoas em dificuldade” para substituí-lo por "pessoa que encontra dificuldades”. A primeira formulação engaja o professor ou o ator social a conceber que a dificuldade está no tema, e então procurar as causas na pessoa come se elas estivessem constitutivamente ancoradas dentro da sua "natureza” (palavra do médico). Eu mostro aos meus estudantes duas seqüências filmadas junto a jovens em instituições psiquiátricas. Um é capaz de dizer, mais rápido que um computador, o dia, o mês ou o ano que apresenta esta ou aquela particularidade em função da questão colocada. O segundo é capaz de tocar no piano, após ouvir somente três vezes, uma melodia escrita com a finalidade de que jamais fosse entendida. Se pegarmos como referência as capacidades dos dois jovens, ninguém entre nós escaparia de uma etiquetagem catastrófica de seus quocientes intelectuais: seríamos seriamente etiquetados "em dificuldade" e submetidos às técnicas "reeducativas" para reparar nossas faltas. Este exemplo mostra que "a dificuldade" não está dentro da nossa "natureza”, mas existe dentro do conflito que nasce entre a demanda social e as possibilidades de resposta que trazemos. Dito de outro modo, a postura do profissional de ação social ou do professor é de trabalhar com o sujeito de modo a transformar esta relação cujos resultados não são satisfatórios de seu ponto de vista e não do nosso. Por isso, torna-se indispensável ao ator social de fazer emergir no Outro os seus potenciais e não contabilizar suas faltas (palavra do contador) a fim de que ele possa ser co-criador de uma nova relação com o seu meio.

\section{Remeter o exilado dele para ele mesmo, a biografização recíproca e o sentido.}


Nós dizíamos logo acima que “a morte” do sujeito vinha também da segmentação e da deslocalização que se pretende aplicar àquele que é. Reunificar o sujeito em um todo, resituá-lo dentro de um espaço social em que ele pode ter as ferramentas de compreensão, é ainda um aspecto daquilo que deveria ser uma política do sujeito dentro do trabalho social. O trabalho de biografização da sua trajetória parece hoje incontornável para aqueles sujeitos parcelizados e desterritorializados (DELORY- MOMBERGUER, 2003, 2005). Sem um trabalho de conscientização e de apropriação do seu percurso, como pode alguém ser sujeito da sua história?

A biografização tende a remeter o exilado dele para ele mesmo. Dentro da ação social, nós sabemos bem que as pessoas excluídas do mundo do trabalho se dessocializam, perdem seus pontos de referência. Se o ator social não tem o tempo de reconstruir com a pessoa uma "consistência” de sua trajetória pessoal, há grandes riscos para que o usuário de um dispositivo social não consiga nunca investir uma posição de sujeito. Mas pode uma intervenção do ator social se reduzir à solicitação uma "narrativa de vida”?

O trabalho de biografização deveria ter a forma de "biografização recíproca” (BIARNÈS, 2006), quer dizer, de um desvendamento recíproco da pessoa e do ator social em um cruzamento, um "viver juntos", onde temos a necessidade de dizer seu passado para compreender o outro no presente e co-construir com ele um futuro. Entregar uma narrativa de vida engendra imediatamente uma dinâmica interpretativa da parte do ator social que coloca o usuário na posição de objeto. A "biografização recíproca” tem o sentido de partilhar, de compreender um outro para conseguir juntos um ato de construção de si mesmo. Ela apresenta a dupla eficácia de "re-situar" o sujeito em um contexto e o levar a recompor o sentido de sua trajetória pessoal. 


\section{Acompanhar o duplo movimento de "inserção / desinserção"}

Uma política do sujeito dentro do trabalho social não pode se conceber sem fazer referência ao duplo movimento de "inserção / desinserção" que constitui o princípio dinâmico do sujeito enquanto processo sempre a ser trabalhado. Isto é o que nós denominamos de jogo narcísico do sujeito. Em efeito, quando o sujeito tenta reduzir o conflito entre as identificações que ele deveria construir "caminhando para o amanhã” e sua própria história tal qual ela é até este dia, ele a faz de maneira a garantir o amor que ele tem por ele mesmo. Isto é o que nós podemos fazer para entrar naquilo que alguns autores chamam de “narcisismo primário”, e aquilo que Freud define como “o retorno da libido sobre os objetos interiorizados” (FREUD, 1912). O sofrimento de dever abandonar certo número de identificações deve encontrar sua compensação imediata na continuação de se amar como é. É bom o que nos mostram os textos dos jovens de 16 a 25 anos encontrando as dificuldades de inserção social e profissional, ao serem acolhidos em um ateliêr de escrita. Nós citamos o exemplo de um texto escrito com o tema da pessoa que gostaríamos de encontrar:

Eu não sei o que dizer, a você que me parece como duas gotas de água. Sem te procurar, eu te encontrei, eu percebi que você tinha os mesmos hábitos que eu, te vendo correr, comer, fumar. Eu não sei como te descrever, mas você é uma réplica de mim mesmo.

No momento em que o sujeito fica em frente a este espelho dele mesmo, ele não fica mais surpreso que o meio ambiente o "veja” limitado dentro das suas possibilidades intelectuais, "simpático" seguramente, em sofrimento sempre. Será necessária toda perspicácia do ator social para entender, além do manifesto, os desejos profundos do "sujeito" e para “retornar” a problemática do sofrimento a crescer no prazer de crescer. 
Assim, “o acompanhamento do sujeito” se torna a importância. Se este último não está mais em torno dele, os adultos que podem ser as referências indispensáveis para, algumas vezes, “alimentá-lo” e lhe "permitir” negociar seus conflitos e os modelos que lhe são propostos, ele adotará a solução do menor sofrimento, aquela de não se mexer. Aprender, crescer, se transformar, não se faz jamais dentro do "silêncio do mundo" como dizia Albert Camus. Ninguém pode aprender sozinho, crescer sozinho, se construir ou se reconstruir sozinho. É sempre um trabalho em interação, em interatividade com os outros.

\section{Uma "política do sujeito" dentro do trabalho social é ainda possível?}

A mundialização, como dissemos, coloca mais e mais "os contadores" nos comandos. Este movimento se amplifica com a descentralização porque as coletividades territoriais foram colocadas em uma contradição que elas tentaram resolver pela via mais simples. De um lado, elas se tornam as "financiadoras" da ação social, e assim, devem ter exigências, e de outro, elas “não sabem fazer”, quer dizer: montar, organizar, animar e avaliar as políticas sociais, uma vez que essa era uma função do Estado. A mundialização e a descentralização fizeram as políticas sociais passarem de meios a uma obrigação de resultados.

Dentro de uma lógica matemática e que se pode contar, para satisfazer uma “obrigação de resultados”, deve-se possuir instrumentos de pilotar confiáveis. Dito de outro modo, não é suficiente fazer uma avaliação final para se perceber as diferenças entre o projeto e a realização, é necessário ter indicadores de vigília ao longo de toda ação com a finalidade de ser advertido em tempo real do menor distanciamento entra as previsões e as realizações. As Missões Locais são assim dotadas de uma lógica, “Percurso 3”, podendo fornecer a cada instante um diagnóstico da situação. 
Para que isto possa ser um instrumento de pilotagem sensível como aqueles que decidem desejam foi construído sobre uma padronização de itens. Nós estamos bem longe da diversidade do público acolhido. Como, e mais ainda, as subvenções das Missões Locais se baseiam sobre um primeiro indicador, que é aquele do número de jovens acolhidos, compreendemos bem que o acolhimento pode vir a ser uma simples sala de apontamentos. E ainda, que o risco deste acolhimento é grande. Além disto, o conselheiro de acolhimento anotar apenas os itens lógicos, com os olhos fixos na tela do computador e não na pessoa com quem ele fala.

Esta visão "produtivista” da ação social é igualmente concretizada pela Lei orgânica das leis de finanças que "recorta” o social em critérios quantitativamente marcados e então avaliáveis. Toda a ação social é hoje considerada da mesma forma que uma atividade de produção de bens. Ela deve se fundar sobre um projeto de resultados em função dos meios colocados à sua disposição e levará em consideração periodicamente o avanço da ação e o resultado final. Os meios serão calculados em função dos resultados obtidos. Evidentemente os critérios quantitativos são aqueles dos financiadores e não aqueles que podem levar em consideração o sujeito. Dentro do programa P.A.Q.U.E. ${ }^{8}$ que teve por objetivo a colocação em emprego ou em formação de qualificação de ao menos 70\% de 1000.000 jovens que saíram dos sistemas educativos sem dominar os conhecimentos de base, uma moça de 20 anos tinha como projeto pessoal aprender a ler para acompanhar e ajudar seu filho que entraria em um curso preparatório. Sua motivação era tão forte que ela conseguiu. De acordo com os critérios do comanditário, ela foi contabilizada como “fracassada”! No entanto, para ela, o sucesso do programa, deveria ter sido medido para a ajuda que pôde dar ao seu filho. Os critérios quantitativos não podem jamais dar conta do real humano.

${ }^{8}$ Programa francês para a inserção de 100.000 jovens sem qualificação profissional. 
Dentro destas condições, uma política do sujeito é ainda possível? Ao trabalhar com os conselheiros de duas Missões Locais no Programa EQUAL $^{9}$ sobre o acompanhamento, nós pudemos construir aquilo que poderia ser um acompanhamento, levando em consideração, ao mesmo tempo, a dimensão quantitativa e a dimensão qualitativa em relação à pessoa enquanto sujeito. Assim, cada etapa da corrente do acompanhamento começa não pela preconização da boa atitude a seguir, mas “das boas questões” a serem colocadas em função daquilo que nós chamamos de “os fundamentos do acompanhamento" para a pessoa seja sujeito de seu percurso.

Os critérios quantitativos, legítimos para o financiador, não devem ser apenas levados em conta na ação social, se não, todos os derivados seriam possíveis. De um lado os atores focalizados sobre estes critérios excluirão de fato o usuário do lugar de sujeito para colocá-lo em situação de objeto de suas próprias ações. Eles mesmos estarão impossibilitados de analisar o sentido desta ação porque ele se limitará a tentar responder ao máximo possível às injunções criadas pelos indicadores. Como os usuários, os atores sociais serão instrumentalizados e então colocados em situação de assujeitamento à política social. Por outro lado, toda a estrutura deverá, para sobreviver e para não deixar seu pessoal desempregado e então em situação de serem os novos beneficiários da ação social, “escolher” seu público. Em função dos objetivos em que a estrutura se fixará, ela deverá selecionar o público que deverá responder melhor e mais rápido possível aos seus objetivos. Estamos de novo na constituição de um sistema em funcionamento sobre ele mesmo, e então, na fabricação de uma máquina excludente a partir de uma estrutura feita para a inserção.

É uma conseqüência urgente que os atores sociais se preocupem em construir seus próprios instrumentos de avaliação do seu trabalho,

\footnotetext{
${ }^{9}$ Programa Europeu de luta contra todas as discriminações.
} 
instrumentos de avaliação qualitativa e não quantitativa. Neste sentido, nós trabalhamos com os enquadramentos de quatorze canteiros de obras de inserção em todo o departamento. Nós tivemos o pretexto de co-construir um “diário de bordo” que poderia servir para o usuário de cada canteiro. As rubricas neste carnê de bordo são somas clássicas: saberes, saber-fazer, saber-ser. Para cada uma destas três rubricas nos criamos “itens”. Cada um deles são avaliáveis de um a cinco, o primeiro marca a ausência de domínio do item, o quinto ao inverso, marca o bom domínio. Estes itens devem ser preenchidos ao final do primeiro, do terceiro e do sexto mês. O ator social preenche um diário "Senhor X” e separadamente, sem contato, o "Senhor X” preenche o seu próprio diário. O encontro entre o ator social e o senhor $\mathrm{X}$ tem por objeto a comparação das duas avaliações e a análise dos desvios e das correspondências entre as anotações. O objetivo último não é "negociar" uma avaliação comum, mas sim compreender as razões que levaram cada um dos avaliadores a fazer como fizeram.

Nós estamos em uma verdadeira dinâmica do sujeito, tanto do lado do usuário como do ator social. A avaliação estabelecida por um ou por outro e sua legitimidade são reconhecidas como tais (levando-se em consideração a palavra e a emergência desta palavra no lugar até então interditado, aquele da sua própria avaliação), mas cada um tem a obrigação de fazer o outro compreender desta legitimidade. Por isso, cada um tem a necessidade de se “desvendar” (biografização recíproca), cada qual tem a necessidade de explicitar seus critérios sob o olhar das situações vividas em comum (re-territorialização da pessoa) e cada um deve tentar permanecer coerente (desparcialização da pessoa dentro dos diferentes percursos). Enfim, com esta técnica de avaliação, o ator social pode ter uma análise qualitativa de sua ação com cada pessoa que ele acompanha e pode confrontá-la com os critérios quantitativos da LOLF.

Uma política do sujeito dentro da ação social é para nós ainda possível, se as estruturas e os atores sociais forem acompanhados em uma 
análise contínua de suas ações, aquela que nos chamamos de "terceiro analisante” (DAHAN, 2005). Manter e desenvolver esta política do sujeito em educação e dentro da ação social é um dos meios de não confrontar um mundo dividido entre dominação e barbárie, é fazer de tal modo que o sentido de humanidade não desapareça. Ele é impedido nos meios de dominação que instalam as regras do engenheiro, do médico e do contador, que matam “o ser sujeito”. Nós poderemos todos, professores e atores sociais prioritariamente, fazer nosso este princípio chamado por Raoul Vaneigem (VANEIGEM, 2004, p. 102) “o humano antes do número”.

Se fazer viver uma política do sujeito tem sido uma questão de ética, é também hoje uma questão de democracia.

\section{Bibliografia}

Beck, U. (2003). Pouvoir et contre pouvoir à l'ère de la mondialisation. Paris :Aubier.

Benasayag, M. (2004). Le Mythe de l’individu. Paris : Éd. La découverte.

Biarnès, J. (1993). Le Projet assassin d'avenir. acte du colloque CREAI, Dijon.

Biarnès, J. (1999). Universalité, diversité, sujet dans l'espace pédagogique. Paris : L’Harmattan.

Biarnès, J. (2006).(à paraître) : "Maintenant je ne suis plus invisible, chantiers d'insertion et politique sociale », in $n^{\circ}$ spécial OSP Insertion, biographisation, éducation. coord. Biarnès J./ DeloryMomberger Ch.

Biarnès, J. \& Azoulay A. (1995). « Le bilan intégré à l'acte formatif », in Les jeunes, l'insertion, l'emploi. Charlot B. \& Glasman D. (coord.), Paris : PUF. 
Bourriaud, N. (2003). Formes de vie, L'art moderne et l'invention de soi. Paris : Denoël.

Dahan, L. (2005). Le Tiers analysant. Mémoire de DEA, CNAM, chaire du Travail Social.

Delory-Momberger, Ch. (2003). Biographie et éducation. Figures de l'individu-projet. Paris : Anthropos.

biographique en éducation. Paris : Anthropos.

(2005). Histoire de vie et recherche

Freud, S. (1912). Totem et tabou. Paris : PUF.

Habermas, J. (1987). Théorie de l’agir communicationnel. Paris : Fayard.

Hamel, G. \& Prahalad (2004). Competing for the future. HBR.

Kauffman, J.C. (2001). Ego. Pour une sociologie de l'individu. Paris : Nathan.

Mongin, O. (2005). La condition urbaine. La ville à l'heure de la mondialisation. Paris : Seuil.

Morin, E. (1992). Introduction à la pensée complexe. Paris : ESF.

Vaneigem, R. (2004). Pour l'abolition de la société marchande, pour une société vivante ». Paris : Payot \& Rivages. 


\section{Jean Biarnès}

Professeur à l’Université Paris 13/Nord Centre interuniversitaire de recherche EXPERICE (Paris 13-Paris 8) jhbiarnes@aol.com

Tradução: Nilce da Silva, Patrícia Fridman e Cláudia Cascapera

\section{Como citar este artigo:}

BIARNES, Jean. Mundialização, trabalho social e política do sujeito. Revista ACOALFAplp: Acolhendo a Alfabetização nos Países de Língua portuguesa, São Paulo, ano 2, n. 4, 2008. Traduzido por : SILVA, Nilce da; FRIDMAN Patrícia e CASCAPERA, Cláudia Disponível em: $<$ http://www.mocambras.org > e ou <http://www.acoalfaplp.org>. Publicado em: março 2008.

Trabalho em francês recebido em setembro de 2006; aprovado em novembro de 2006./ Tradução de fevereiro de 2008. 